\title{
A Dumbbell-shaped Meningioma in the Thoracic Spine: A Case Report
}

\author{
Can Yaldiz ${ }^{1 *}$, Kiyasettin Asil $^{2}$, Davut Ceylan ${ }^{1}$ and Sahin Erdem ${ }^{3}$ \\ ${ }^{1}$ Department of Neurosurgery, Sakarya University Training and Research Hospital, Sakarya-Turkey \\ ${ }^{2}$ Department of Radiology, Sakarya University Training and Research Hospital, Sakarya, Turkey \\ ${ }^{3}$ Department of Pathology, Sakarya University Training and Research Hospital, Sakarya, Turkey
}

*Corresponding author: Can Yaldiz, Department of Neurosurgery, Sakarya University Training and Research Hospital, Adnan Menderes Cad. Sağlık Sok. No: 195 Sakarya, Turkey 54010; Tel: +90 (264)275 00 90-1460; Fax: +90(264) 27591 92, E-mail: drcanyaldiz@yahoo.com

Rec date: Mar 26, 2014, Acc date: May 23, 2014, Pub date: May 28, 2014

Copyright: $\odot 2014$ Yaldiz C, et al. This is an open-access article distributed under the terms of the Creative Commons Attribution License, which permits unrestricted use, distribution, and reproduction in any medium, provided the original author and source are credited.

\section{Abstract}

Background Context: Thoracic involvements of meningiomas are rarely seen and only a couple of dumbbellshaped meningiomas are reported in the literature. Spinal meningiomas (SM) consist of $25 \%$ of all spinal masses. Most of the SMs are intradural. Less than $10 \%$ have extradural extension.

Purpose: Pure spinal extradural meningiomas (SEM) are seen so rare. We are reporting the $7^{\text {th }}$ case of meningioma with dumbbell-appearance located in the cervicothoracal region.

Methods: 48 years old female patient who has no known disease before she has referred to our clinic with complaints of pain, feeling of numbness at the right arm, shoulder and the back that she has been suffering for 6 months. In the neurological examination of the patient, hypoesthesia has seen under the level of Th1. Deep tendon reflexes of the lower extremities (DTR) were observed to be suspicious bilaterally in respect to hyperactivity. In the spinal magnetic resonance imaging (MRI) of the patient), after Gadolinium infusion of the mass involving the epidural area in the spinal channel of the bone between $\mathrm{C} 7$ vertebra and T2 vertebrae, resulting in dumbbell appearance, a lesion with homogenous contrast enhancement was observed.

Results: T1 total laminectomy was applied to the patient. The mass found in the extradural region and extending to the apex of the right lung was totally removed with micro chirurgical method. Pathology of the mass was reported as psammomatous meningioma. The patient was discharged at the post-operative 3rd day without an additional neurologic deficit.

Conclusion: Though extradural spinal meningiomas are rarely seen, since they imitate spinal metastatic masses, should be kept in mind in the differential diagnosis. Surgery should be the first treatment of choice.

Keywords: Extradural tumor; Spinal tumor; Meningioma

\section{Introduction}

Spinal meningiomas (SMs) account for $25 \%$ of all spinal masses. Sixty-four percent of SMs are seen in the thoracic region, $28 \%$ are found in the cervical region, and $8 \%$ are seen in the lumbar region. Most SMs are intradural, and less than $10 \%$ have extradural extension [1]. Pure spinal extradural meningiomas (SEMs) are rarely seen, and only a couple of dumbbell-shaped meningiomas are reported in the literature [2]. The mechanisms of SEM formation are not clear, but arachnoid cells along the peripheral nerves take the blame in the pathology [1]. We are presenting a case of a meningioma with a dumbbell appearance located in the cervicothoracic region.

\section{Case}

A 50-year-old female patient was referred to our polyclinic with complaints of back pain and numbness of the right arm and shoulder that she had been experiencing for 6 months. During neurological examination of the patient, hypoesthesia under the level of T1 was noted and 4-5/5 muscle strength was present in the intrinsic muscles of both hands. The triceps reflex was hyperactive on the right side. Bilateral muscle strength was detected to be $5 / 5$ on motor examination of the lower extremities. Deep tendon reflexes (DTRs) of the lower extremities were observed to be bilaterally slightly hyperactive. A mass originating from the spinal canal and extending to the hemithorax from the right paravertebral area at the level of the T1 vertebra and extending toward the T1 bony spinal canal was observed on CT scan (Figure 1). The mass involved the epidural area of the spinal canal and the bone between the $\mathrm{C} 7$ and T2 vertebrae, resulting in a dumbbellshaped appearance. A lesion showing homogenous contrast enhancement after gadolinium infusion was observed on MR images (Figure 2).

Preliminary preparations for surgery were performed on the patient, who was considered to have a schwannoma as the initial radiological diagnosis. The extradural mass was totally excised microsurgically. The pathology of the mass was reported as psammomatous meningioma (Figure 3A-3C). The patient was discharged 3 days after surgery without additional neurological deficits. 
Citation: Yaldiz C, Asil K, Ceylan D and Erdem S (2014) A Dumbbell-shaped Meningioma in the Thoracic Spine: A Case Report . J Spine 3: 168. doi:10.4172/2165-7939.1000168

Page 2 of 4

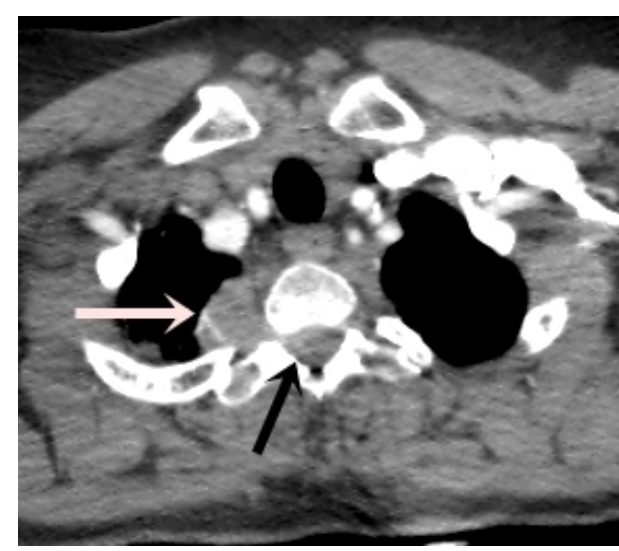

Figure 1: Thoracic extension of the mass in CT examination at the axial plane (white arrow) and its component in the spinal channel (black arrow) are observed.

\section{Discussion}

Many hypotheses on the etiological occurrence of SMs exist. The first hypothesis states that the dura surrounding the nerve root originates from the arachnoid membrane. The second states that SMs originate from arachnoid residues found in the epidural region. This opinion is supported by a few case presentations related to meningiomas, with extracranial localizations and optical nerve origins. The third hypothesis states that SMs originate from the "cap" cells found directly on the surface of the dura $[1,3,4,6]$.

Some clinical factors are inclined in the formation of spinal meningiomas. These include spinal trauma, radiotherapy performed for breast adenocarcinoma, and intracranial ependymoma [1,6]. SMs are seen more frequently in females than in males ( $4: 1$ ratio). In our case, the patient was female and none of these etiological factors were present.
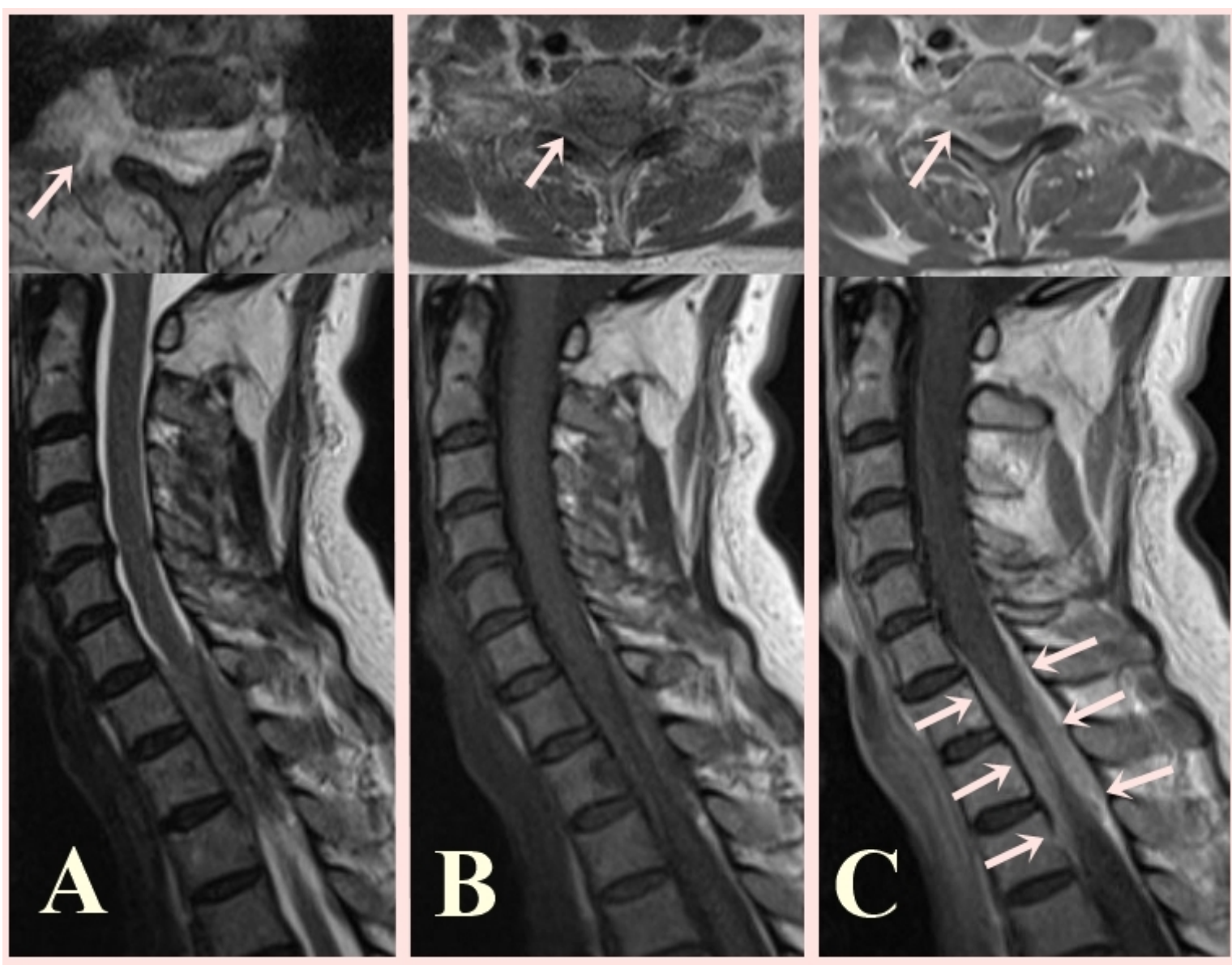

Figure 2: MRI appearance of the mass (white arrows) 2A) Hyperintense mass in T2 weighted series at the axial and sagittal planes, 2B) isohypointense mass in T1 weighted series at the axial and sagittal planes, 2C) mass with homogenous contrast enhancement in T1 weighted series with gadolinium at the axial and sagittal planes. Results in dumbbell appearance at the sagittal plane. 
Citation: Yaldiz C, Asil K, Ceylan D and Erdem S (2014) A Dumbbell-shaped Meningioma in the Thoracic Spine: A Case Report . J Spine 3: 168.

Page 3 of 4

The area between the parietal pleura and the thoracic wall above the lungs is called the extrapleural area. Connective tissue, veins and nerves are found in this cavity and pathological formations like infection, myeloma, lymphoma, primary tumors, schwannomas, and desmoid tumors are frequently seen. Meningiomas are rarely seen in this anatomical region $[2,4]$.
Expansion of SMs into the endothoracic region is rarely seen. Only 6 cases of a dumbbell appearance in meningiomas originating from the thoracic vertebrae are found in the literature. Our case is the $7^{\text {th }}$ case (Table 1).
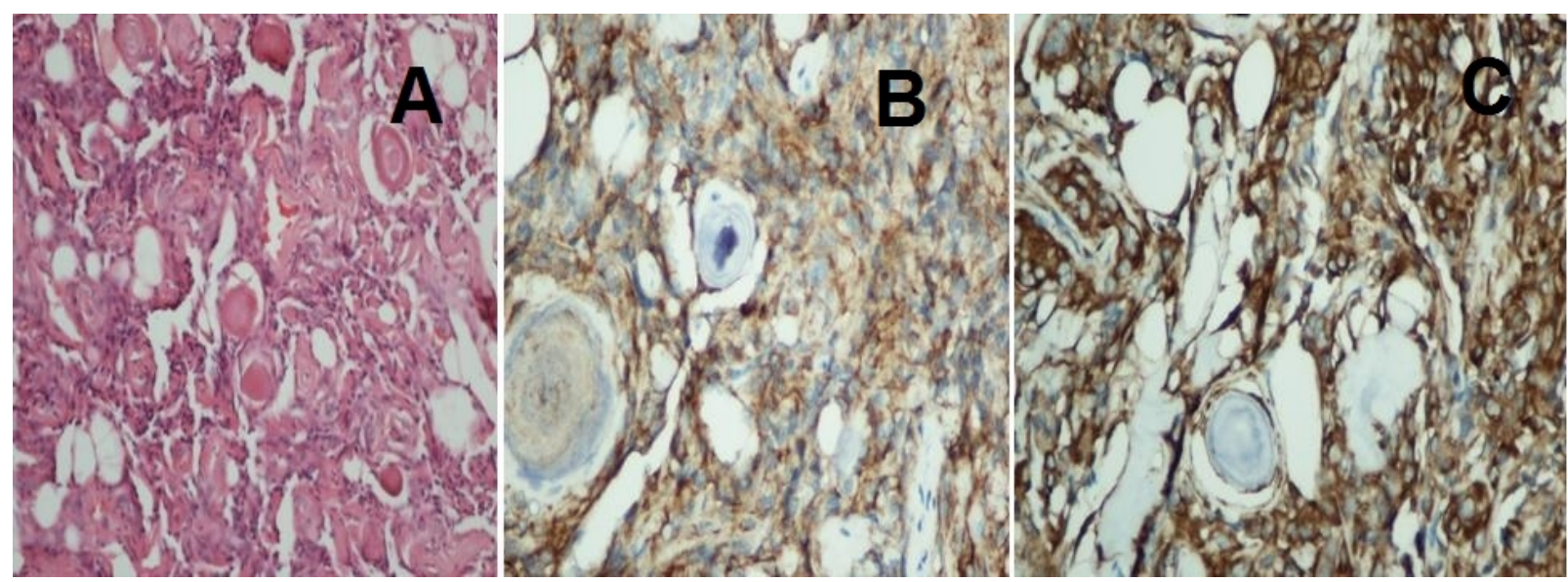

Figure 3: A: H\&E x200, B: EMA positivity by immunohistochemical (x400) C: Vimentin positivity by immunohistochemical ( $\mathrm{x} 400$ ).

\begin{tabular}{|c|c|c|c|c|c|c|}
\hline Reference/year & Age/sex & Localization & Clinic & Surgery & Pathology & Result \\
\hline Buchfelder M [3] & $76-\mathrm{F}$ & & & $\begin{array}{l}\text { Laminectomy+ } \\
\text { thoracotomy }\end{array}$ & meningioma & Total \\
\hline Suzuki A [4] & $58-\mathrm{M}$ & T10-T11-T12 & $\begin{array}{l}\text { Normal. abnormal } \\
\text { mass on the chest } \\
\text { radiograph. }\end{array}$ & $\begin{array}{l}\text { T11-T12 } \\
\text { hemilaminectomy+ } \\
\text { thoracoscope }\end{array}$ & $\begin{array}{l}\text { fibroblastic } \\
\text { meningioma }\end{array}$ & $\begin{array}{l}\text { Total excision, no } \\
\text { complaints }\end{array}$ \\
\hline Restrepo CS [2] & $57-\mathrm{F}$ & $\mathrm{C} 7-\mathrm{T} 2$ & $\begin{array}{lr}\text { Loss of } & \text { strength } \\
\text { in the lower } \\
\text { extremity, } \\
\text { increase } \\
\text { reflexes }\end{array}$ & $\begin{array}{l}\text { Total laminectomy }+ \\
\text { adjuvant RT }\end{array}$ & $\begin{array}{l}\text { Psammomatous } \\
\text { meningioma, } \\
\text { infiltration }\end{array}$ & $\begin{array}{l}\text { Total excision, no } \\
\text { recurrence }\end{array}$ \\
\hline Santiago BM [5] & $42-M$ & T2-T3 & paraparesis & T2-T3 laminectomy & $\begin{array}{l}\text { Psammomatous } \\
\text { meningioma, }\end{array}$ & Total excision- \\
\hline Kim MS [6] & $50-\mathrm{M}$ & T6-T7 & T6 paresthesia & hemi-laminectomy of T6 & $\begin{array}{l}\text { Meningothelial meningi } \\
\text { oma }\end{array}$ & $\begin{array}{l}\text { Total excision, no } \\
\text { complaints }\end{array}$ \\
\hline Shrestha R [7] & $45-\mathrm{F}$ & T9-T10 & $\begin{array}{l}\text { Normal (during } \\
\text { check-up) }\end{array}$ & $\begin{array}{l}\text { T9-10 total laminectomy+ } \\
\text { Thoracoscopic surgery }\end{array}$ & meningioma & $\begin{array}{l}\text { Total excision, no } \\
\text { complaints }\end{array}$ \\
\hline Our case 2014 & $50-\mathrm{F}$ & $\mathrm{T} 1$ & $\begin{array}{l}\text { Numbness at the } \\
\text { left arm, C7 T1 } \\
\text { left hypoesthesia }\end{array}$ & $\mathrm{T} 1$ total laminectomy & $\begin{array}{l}\text { Psammomatous } \\
\text { meningioma }\end{array}$ & $\begin{array}{l}\text { Total excision, no } \\
\text { additional deficit }\end{array}$ \\
\hline
\end{tabular}

Table 1: Dumbbell-appearance in meningioma originating from the thoracic vertebra

The radiological technique that leads to the best diagnosis of SMs is spinal MRI. SMs are mostly seen as isointense on T1 and T2 images on MRI examination, and can rarely be hypointense on T1 images and hyperintense on T2 images. SMs mostly show homogenous contrast enhancement on MRI examinations done with contrast. Spinal meningiomas are isointense on $\mathrm{T} 1$ slices of the spinal cord and hyperintense on T2 slices. Contrast enhancement is nearly homogenous in all SMs. Bone erosion is frequently seen in meningiomas, as it is in regional tumors such as schwannomas and neurofibromas, and is observed especially in advanced cases $[1,2,4,6,7]$. Our case was consistent with the literature.

According to the WHO classification, radiotherapy and chemotherapy are not required for benign masses. Administration of radiotherapy after subtotal resection is controversial. Mortality and morbidity ratios are low in recurrent meningiomas (0-3\%) [1].

According to the WHO classification of spinal meningioma histopathology, grade 1 meningiomas are most often encountered, 
Citation: Yaldiz C, Asil K, Ceylan D and Erdem S (2014) A Dumbbell-shaped Meningioma in the Thoracic Spine: A Case Report . J Spine 3: 168.

with an incidence of $85.7 \%$, and $57.4 \%$ of them are meningotheliomatous meningiomas. Grade 4 meningiosarcoma is rarely seen, with an incidence of $2.5 \%$. In our patient, the excision material was an off-white color with dimensions of $2 \times 2 \mathrm{~cm}$ on macroscopic examination. At the end of the evaluation, it was determined to be a WHO grade 1 meningioma $[1,2,4,6,7]$.

\section{Conclusion}

Though extradural spinal meningiomas are rarely seen, they should be kept in mind in the differential diagnosis since they imitate schwannoma. Surgery should be the first treatment of choice.

\section{References}

1. Ceylan D, Yaldiz C, Tokmak M, Ozek E, Iplikcioglu AC (2013) Spinal Extradural Meningioma Located at the Thoracocervical Junction: A Case Report. Turk nörosirurji dergisi. 23: 298-302.
2. Restrepo CS, Herrera DA, Lemos JA (2006) Extraforaminal meningioma with extrapleural space extension. AJR Am J Roentgenol 186: 1314-1316.

3. Buchfelder M, Nomikos P, Paulus W, Rupprecht H (2001) Spinalthoracic dumbbell meningioma: a case report. Spine (Phila Pa 1976) 26: 1500-1504.

4. Suzuki A, Nakamura H, Konishi S, Yamano Y (2002) Dumbbell-shaped meningioma with cystic degeneration in the thoracic spine: a case report. Spine (Phila Pa 1976) 27: E193-196.

5. Santiago BM, Rodeia P, Cunha E Sa M (2009) Extradural thoracic spinal meningioma. Neurol India 57: 98.

6. Kim MS, Eun JP, Park JS (2011) A dumbbell-shaped meningioma mimicking a schwannoma in the thoracic spine. J Korean Neurosurg Soc 50: 264-267.

7. Shrestha R, Chen H, Siqing H (2012) Dumbbell meningioma of the thorocic spine resected by combined posterior and thoracoscopic approach. Nepal journal of neuroscience 9: 41-43. 